\title{
EDITORIAL
}

\section{CORONAVIRUS COVID-19}

Ma Aranzazu López Franco (1) y Pello Latasa Zamalloa (2)

(1) Revista Española de Salud Pública. Ministerio de Sanidad. Madrid. España.

(2) Centro de Alertas y Emergencias Sanitarias. Ministerio de Sanidad. Madrid. España.

A finales de diciembre de 2019 apareció una nueva zoonosis por primera vez en la ciudad china de Wuhan, la cual acabaría por colarse en las agendas de todos los países del mundo. En un tiempo récord se identificó el agente causal y empezó hablarse ya, dentro del ámbito sanitario, de un nuevo coronavirus que sería denominado como SARS-CoV-2 por la Organización Mundial de la Salud (OMS) el 11 de febrero de $2020^{(1)}$, el cual ocasiona la enfermedad conocida como Covid-19.

A medida que llegaban nuevos datos procedentes de China sobre la epidemia y el país asiático comenzaba a implementar sus drásticas medidas de contención que copaban cabeceras de telediarios y portadas de periódicos, las autoridades sanitarias del resto de países del mundo iban recopilando información y tratando de anticipar una respuesta proporcionada ante la amenaza de una enfermedad que fue declarada definitivamente como pandemia por la OMS el 11 de marzo de $2020^{(2)}$.

Todos los que trabajamos en la Revista Española de Salud Pública (RESP) estamos colaborando de una u otra manera en la gestión de esta crisis, quizá en aspectos menos relevantes, pero a nuestro parecer importantísimos, como son la comunicación o la atención al ciudadano que nos hace llegar sus consultas sobre la pandemia.
Sin embargo, la revista, como ya habrán podido comprobar, ha seguido su ritmo habitual publicando una media de dos o tres artículos a la semana, realizando un esfuerzo importante, porque la situación lo requiere y porque, como cualquiera que trabaje en periodismo científico sabe, esta profesión casi siempre se transforma en una pasión para quien la ejerce.

Queremos agradeceros a todos los profesionales sanitarios e investigadores que durante estos días nos estáis haciendo llegar vuestros trabajos. Sabemos cuán difícil es en estos momentos mantener la tensión y seguir con una normalidad que ya no existe. En particular, gracias a los que nos habéis enviado artículos sobre el SARS-CoV-2 y Covid-19. Se va a priorizar su gestión editorial. Igualmente, agradeceros a todos aquellos que seguís revisando estos manuscritos. Recordaros, por último, que disponemos de una sección en la que se pueden publicar protocolos de investigación.

Nos gustaría devolver toda esta entrega y, por eso, en la RESP estamos preparando algunas novedades que esperamos puedan cristalizar en las próximas semanas para, desde la objetividad del conocimiento científico, contribuir en la medida de lo posible a ampliar la información sobre este virus dentro de la comunidad de profesionales de la salud pública que componen nuestros lectores. 


\section{BIBLIOGRAFÍA}

1. World Health Organization. Naming the coronavirus disease (COVID-19) and the virus that causes it. 11.02.2020. Disponible en: https://www.who.int/emergencies/diseases/ novel-coronavirus-2019/technical-guidance/naming-the-coronavirus-disease-(covid-2019)-and-the-virus-that-causes-it.

2. World Health Organization. WHO Director-General's opening remarks at the media briefing on COVID-19 - 11 March 2020. 11-03-2020. Disponible en: https://www.who. $\mathrm{int} / \mathrm{dg} /$ speeches/detail/who-director-general-s-opening-remarks-at-the-media-briefing-on-covid-19---11-march-2020. 